STUDI

FRANCESI

\section{Studi Francesi}

Rivista quadrimestrale fondata da Franco Simone

165 (LV | III) | 2011

LA RAPPRESENTAZIONE DELLA MADRE NELLA

LETTERATURA FRANCESE DEL NOVECENTO a cura di Dario Cecchetti e Michele Mastroianni

\title{
Dominique Combe, Les littératures francophones. Questions, débats, polémiques
}

\section{Carminella Biondi}

\section{(2) OpenEdition \\ Journals}

\section{Edizione digitale}

URL: http://journals.openedition.org/studifrancesi/5162

DOI: $10.4000 /$ studifrancesi.5162

ISSN: 2421-5856

\section{Editore}

Rosenberg \& Sellier

\section{Edizione cartacea}

Data di pubblicazione: 1 décembre 2011

Paginazione: 684-685

ISSN: 0039-2944

Notizia bibliografica digitale

Carminella Biondi, «Dominique Combe, Les littératures francophones. Questions, débats, polémiques», Studi Francesi [Online], 165 (LV | III) | 2011, online dal 30 novembre 2015, consultato il 08 janvier 2021 URL: http://journals.openedition.org/studifrancesi/5162 ; DOI: https://doi.org/10.4000/studifrancesi. 5162

Questo documento è stato generato automaticamente il 8 janvier 2021.

\section{(†) $\ominus$

Studi Francesi è distribuita con Licenza Creative Commons Attribuzione - Non commerciale - Non opere derivate 4.0 Internazionale. 


\title{
Dominique Combe, Les littératures francophones. Questions, débats, polémiques
}

\author{
Carminella Biondi
}

\section{NOTIZIA}

DOMINIQUE COMBE, Les littératures francophones. Questions, débats, polémiques, Paris, PUF, «Licence», 2010, pp. 242.

1 Come indica il titolo, il noto studioso di poetica e teoria letteraria si propone di fare un bilancio del dibattito attorno alle letterature francofone che si è avviato negli anni Sessanta dello scorso secolo, al momento della fine delle colonie francesi, e che è stato rilanciato con forza dal manifesto Pour une littérature-monde en français, pubblicato su «Le Monde» il 15 marzo 2007, un manifesto che si presenta come la pietra tombale della francofonia: «Fin de la francophonie. Et naissance d'une littérature-monde en français». Dopo una introduzione in cui vengono indicate le finalità dell'autore e poste le basi del discorso critico che segue, il volume si organizza in sei ampi capitoli che tracciano un panorama esaustivo della storia della francofonia dalle origini (il termine è creato dal geografo Onésime Reclus intorno al 1880) fino ai giorni nostri e dei problemi che ne hanno accompagnato il percorso.

2 Nel primo capitolo che si intitola, con un chiaro rinvio a Montesquieu, «Comment peuton être francophone?», il critico ritraccia la storia di un'etichetta quanto mai discussa e stabilisce una netta distinzione fra l'uso del termine scritto con la lettera minuscola o maiuscola, considerando quest'ultimo come una «invention post(coloniale)» (pp. 37-41). Il secondo capitolo, «Littératures francophones, littératures anglophones?», si sofferma sui diversi modi di declinare realtà analoghe in ambito francese e inglese, mentre il terzo capitolo, intitolato «Les francophonies plurilingues», affronta in maniera molto dettagliata tutti i problemi legati alla situazione delle ex-colonie, 
caratterizzate dalla presenza di più lingue, come indicano i paragrafi che scandiscano la materia del capitolo: “Monolinguisme de l'autre', 'littérature mineure', et 'surconscience linguistique'»; «Plurilinguismes, bilinguismes?»; «Dyglossies, polyglossies», a loro volta suddivisi in numerosi sotto-paragrafi. Il passaggio al capitolo seguente, intitolato «Plurilinguisme et traduction» è del tutto naturale: vi viene affrontato in particolare il problema dell'autotraduzione, molto comune appunto in aree uscite dalla colonizzazione europea, un'autotraduzione che spesso assume le caratteristiche di una vera e propria riscrittura.

Il capitolo quinto affronta il tema cruciale, soprattutto in ambito postcoloniale, delle appartenenze culturali: «Littératures francophones et identités nationales à l'heure de la mondialisation». Nel paragrafo conclusivo, che pone la questione delle questioni, ossia quella che riguarda l'identità («Identités nationales ou trasnsantionales? L'exemple américain», pp. 85-187), l'autore legge la realtà americana come paradigma di una "rottura" del fronte della francofonia, perché nello stabilire le appartenenze culturali, entrano in gioco parametri di valutazione che prescindono dalla lingua: «Du Québec aux Antilles, des liens multiples se nouent, qui appellent à réfléchir à une spécificité continentale et transnationale des littératures d'Amérique, des Amériques, en évitant cependant d'“essentialiser" cette spécificité» (p. 185). Per esempio, la vastità degli spazi americani condurrebbe naturalmente gli scrittori a privilegiare il racconto epico, quale che sia la lingua utilizzata e dunque a travalicare le caratteristiche della loro appartenenza ad aree culturali etichettate su base linguistica, per ritrovare una comune unità "geografica" che le trascende.

4 Il punto d'approdo inevitabile del volume è quello delle scritture migranti, affrontate nel sesto capitolo («Littératures francophones, écritures "migrantes"»), che si apre con un paragrafo sulla terminologia di volta in volta utilizzata per indicare lo spostamento dal proprio luogo d'origine ad un luogo altro $o$, come accade sempre più spesso, il fenomeno dell'erranza che non prevede luoghi d'approdo. I termini analizzati da Dominique Combe: "exil", "migrance", "migration", "diaspora", indicano lo stesso fenomeno dello spostamento, ma realizzato in condizioni diverse. Il termine più innovativo, come ben sanno gli studiosi di letterature postcoloniali, è «migrance», che tende oggi ad imporsi "comme une catégorie centrale pour la théorie postcoloniale, avec l'"hybridité", la "liminalité" ou le "subalterne" [...]. La "migrance" est ainsi le mode d'être propre au XxI siècle» (pp. 196-197). Segue un paragrafo su "Les littératures de l'immigration en France» ed uno su «Les écritures 'migrantes' au Québec», viste come uno dei fenomeni più interessanti della francofonia letteraria del ventunesimo secolo.

5 Termina il volume, in guisa di conclusione problematica, l'interrogativo sulla morte della francofonia: «Des litératures francophones à la "littérature-monde en français?», che analizza in termini piuttosto critici l'approdo all'ultimo avatar della riflessione sulle letterature di lingua francese, la "littérature-monde", appunto. Dominique Combe pone dapprima il problema del declino della cultura francese in generale per passare poi alla specifico con un altro interrogativo: «La fin de la "Francophonie"?», a cui risponde in maniera negativa citando le parole dure che lo scrittore libanese Alexandre Najjar ha usato nei confronti del manifesto: «la notion de "littérature-monde en français" ne veut rien dire, elle n'est qu'une périphrase de la francophonie qui est l'ensemble de ceux qui, aux quatre coins du monde, ont le français en partage. "Il a expliqué l'eau par l'eau" dit un proverbe libanais» (p. 217, l'articolo di Najjar era apparso su «Le Monde» il 30 marzo 
2007). Il problema posto dal manifesto dei 40 è forse un po' più complesso ma, per quanto concerne le letterature francofone, si ha l'impressione di essere ritornati al punto di partenza. I dibattiti e le polemiche, lungi dal portare ad una soluzione condivisa, sembrano imbrogliare le carte; sono tuttavia indubbiamente interessanti perché esprimono un disagio reale di fronte ad un concetto, quello di francofonia - sia pure declinato nella sua versione plurale e con l'aggiunta del termine letterature - che si percepisce ancora come troppo connotato dalla colonizzazione e dal dominio della Francia sulle aree periferiche.

6 Un lavoro fondamentale, quello di Dominique Combe, non solo per ripercorrere la storia dei dibattiti sulle letterature francofone e per fare il punto della situazione in questo ambito, ma anche per interrogarsi sullo stato di salute della cultura francese di Francia e per riflettere, più in generale, sui problemi concernenti gli studi postcoloniali. 